\title{
Genetic relationships between body condition score and reproduction traits in Canadian Holstein and Ayrshire first-parity cows
}

\author{
C. Bastin, ${ }^{* 1}$ S. Loker, $†$ N. Gengler, ${ }^{\star} \ddagger$ A. Sewalem, $§ \#$ and F. Miglior§\# \\ *University of Liège, Gembloux Agro-Bio Tech, Animal Science Unit, B-5030 Gembloux, Belgium \\ †Center for the Genetic Improvement of Livestock, University of Guelph, Guelph, Ontario, N1G 2W1, Canada \\ $\ddagger$ National Fund for Scientific Research, B-1000 Brussels, Belgium \\ $\S$ Guelph Food Research Centre, Agriculture and Agri-Food Canada, Guelph, Ontario, N1G 5C9, Canada \\ \#Canadian Dairy Network, Guelph, Ontario, N1K 1E5, Canada
}

\section{ABSTRACT}

The objective of this study was to investigate the genetic relationship between body condition score (BCS) and reproduction traits for first-parity Canadian Ayrshire and Holstein cows. Body condition scores were collected by field staff several times over the lactation in herds from Québec, and reproduction records (including both fertility and calving traits) were extracted from the official database used for the Canadian genetic evaluation of those herds. For each breed, six 2-trait animal models were run; they included random regressions that allowed the estimation of genetic correlations between BCS over the lactation and reproduction traits that are measured as a single lactation record. Analyses were undertaken on data from 108 Ayrshire herds and 342 Holstein herds. Average daily heritabilities of BCS were close to 0.13 for both breeds; these relatively low estimates might be explained by the high variability among herds and BCS evaluators. Genetic correlations between BCS and interval fertility traits (days from calving to first service, days from first service to conception, and days open) were negative and ranged between -0.77 and -0.58 for Ayrshire and between -0.31 and -0.03 for Holstein. Genetic correlations between BCS and 56-d nonreturn rate at first insemination were positive and moderate. The trends of these genetic correlations over the lactation suggest that a genetically low BCS in early lactation would increase the number of days that the primiparous cow was not pregnant and would decrease the chances of the primiparous cow to conceive at first service. Genetic correlations between BCS and calving traits were generally the strongest at calving and decreased with increasing days in milk. The correlation between BCS at calving and maternal calving ease was 0.21 for Holstein and 0.31 for Ayrshire and emphasized the relationship between fat

Received September 11, 2009

Accepted January 13, 2010.

${ }^{1}$ Corresponding author: catherine.bastin@ulg.ac.be cows around calving and dystocia. Genetic correlations between calving traits and BCS during the subsequent lactation were moderate and favorable, indicating that primiparous cows with a genetically high BCS over the lactation would have a greater chance of producing a calf that survived (maternal calf survival) and would transmit the genes that allowed the calf to be born more easily (maternal calving ease) and to survive (direct calving ease).

Key words: body condition score, fertility, calving ease, genetic correlation

\section{INTRODUCTION}

Management of reproductive performance (including fertility and calving traits) is an important issue to the dairy industry. Decreased fertility is a very topical problem and has been documented over the last few years by several authors (Lucy, 2001). For instance, VanRaden et al. (2004) indicated that the number of days between calving and conception (or days open) increased from 110 to 140 between 1965 and 2000 in the United States. The decline in fertility is probably due to a combination of physiological and management factors that have an additive effect on reproductive efficiency (Lucy, 2001). Among other factors, the extent and the duration of the postpartum negative energy balance strongly influences the fertility of the dairy cow (Butler and Smith, 1989). However, because of the difficulty of routinely measuring the energy balance status, indirect indicators such as BCS are commonly used. Body condition score assesses the stored energy reserves of the dairy cow and is therefore linked to energy balance status and fertility. Previous studies estimated the genetic correlations between fertility traits and BCS using multivariate analyses and suggested that cows with a genetically low BCS tend to have poorer fertility (Dechow et al., 2001; Pryce et al., 2001; Berry et al., 2003a).

Calving traits are among the most important functional traits because of their association with economi- 
cally important traits such as fertility, longevity, and milk production (Dematawewa and Berger, 1997). Some risk factors of dystocia have been identified such as parity, sex, and weight of the calf, age at first calving, or season (Meijering, 1984; Berry et al., 2007). Moreover, some studies investigated the phenotypic relationship between BCS and calving traits and indicated that a high BCS before calving could increase the risk of dystocia and consequently stillbirth (Chassagne et al., 1999). To our knowledge, the genetic relationship between BCS and calving traits has not been investigated.

Previous studies concerning the genetic relationship between fertility and BCS considered BCS at different stages of lactation as different traits (e.g., BCS at calving or BCS postpartum). However, as shown by Veerkamp et al. (2001) and Berry et al. (2003b), using random regression models allows the estimation of genetic correlations between BCS over the lactation and traits that are measured as a single lactation record. This approach allows the estimation of the change of the correlations between BCS and reproduction traits across the lactation

The objective of this research was to estimate genetic correlations between BCS and reproduction traits for first-parity Canadian Holstein and Ayrshire cows, using random regression models. This research is part of a larger project to develop a genetic evaluation for BCS in Canada.

\section{MATERIALS AND METHODS}

\section{Data Editing}

In Canada, BCS is recorded via 2 separate systems. First, BCS has been recorded on a scale from 1 to 5 in increments of 0.25 (Edmonson et al., 1989) on a large number of Québec herds by the field staff of Valacta (the Canadian DHI organization responsible for Québec and Atlantic provinces) since 2001, mainly for management purposes. More recently, BCS has been recorded nationwide, also on a scale from 1 to 5 in increments of 0.25 , since June 2006 as a research trait by breed classifiers during the routine type classification. Whereas the latter system generally records one observation per cow per lactation, several records are available per cow per lactation from the first system. The number of data from the classification system is still limited; therefore, only data from Valacta were used in this study.

Ayrshire and Holstein BCS were collected between January 2001 and September 2008 from herds in Québec, Canada. Scores were available for cows in the first 3 parities. Body condition score could be recorded several times during lactation and during the dry period. The same scale was used in both breeds, and the same group of BCS assessors scored Holstein and Ayrshire cows. On average, 2.4 and 2.7 BCS records were available per cow per parity for Ayrshire and Holstein cows, respectively. Herds with $<5$ cows recorded across the data set were deleted. Across the data set, herds had to have a BCS standard deviation $>0.25$. Then, BCS records were deleted for a given herd $\times$ test-day if $<5$ records were taken at that herd $\times$ test-day. These criteria were chosen so that the data set included records from herds that recorded BCS regularly and in a reliable way. Finally, BCS records taken after 335 DIM were deleted and cows with a dry period $>80 \mathrm{~d}$ were eliminated.

Reproduction records used for the Canadian genetic evaluation were then extracted from the official database of the Canadian Dairy Network. Records were kept for herds with at least 1 cow with both BCS records and one of the following traits: 1) days between calving and first service (CTFS), 2) days between first service and conception (FSTC), 3) days open (DO), 4) 56-d nonreturn rate at first insemination (NRR), 5) calving ease $(\mathbf{C E})$, and 6) calf survival (CS). Nonreturn rate was coded 1 when there was no subsequent insemination between 15 and $56 \mathrm{~d}$ following the first service, and 0 otherwise. Because NRR is used as an early indication of conception rate, NRR data have not been validated with a subsequent calving date. Therefore, true pregnancy rate might have been overestimated because cows that were sold or culled or cows that returned but were served by a natural-service farm sire were not taken into account. Conception date was determined using the subsequent calving date that agreed with the latest insemination data. Calving difficulty was scored in 4 classes from 1 (unassisted calving) to 4 (surgery). In this study, the trait will be called calving ease to stay in agreement with official Canadian practice. Calf survival was defined as 0 (dead within $24 \mathrm{~h}$ from birth) and 1 (alive).

After editing the data set, only records from the first parity were kept, as this was a preliminary study. Because a random regression model was used, cows were limited to at least 2 BCS records, 1 before 60 DIM and 1 after 60 DIM. Moreover, at least 2 observations per class of each effect (except animal effect) were required. After those edits, 3.7 and 4.0 BCS records were available on average per cow for Ayrshire and Holstein, respectively. Whereas the complete data set was used for the variance component estimation for Ayrshire cows, 5 random samples of complete herds were extracted from the edited Holstein data set. Numbers of data and numbers of cows after editing are given in Tables 1 and 2. For Ayrshire, data included 9,739 BCS observations and 9,525 to 10,768 reproduction records depending on the trait. These data included 11,975 
Table 1. Descriptive statistics of the edited first-parity Ayrshire data set for each model: BCS with one of the following traits: calving to first service (CTFS), first service to conception (FSTC), days open (DO), 56-d nonreturn rate at first insemination (NRR), calving ease (CE), and calf survival (CS)

\begin{tabular}{lcccccc}
\hline & \multicolumn{4}{c}{ Model } \\
\cline { 2 - 6 } Item & BCS - CTFS & BCS - FSTC & BCS - DO & BCS - NRR & BCS - CE & BCS - CS \\
\hline BCS records, $\mathrm{n}$ & 9,739 & 9,739 & 9,739 & 9,731 & 9,739 & 9,739 \\
Reproduction records, $\mathrm{n}$ & 11,950 & 10,621 & 10,621 & 10,996 & 12,042 & 11,633 \\
Mean BCS \pm SD & $2.87 \pm 0.40$ & $2.87 \pm 0.40$ & $2.87 \pm 0.40$ & $2.87 \pm 0.40$ & $2.87 \pm 0.40$ & $2.87 \pm 0.40$ \\
Mean reproduction trait \pm SD & $87.00 \pm 27.77$ & $32.43 \pm 43.29$ & $119.25 \pm 49.73$ & $0.56 \pm 0.50$ & $1.34 \pm 0.58$ & $0.92 \pm 0.27$ \\
Cows with records, $\mathrm{n}$ & 13,057 & 11,975 & 11,975 & 12,232 & 14,683 & 14,274 \\
Cows with both records, $\mathrm{n}$ & 1,535 & 1,288 & 1,288 & 1,402 & 1,958 & 1,920 \\
\hline
\end{tabular}

to 14,683 cows with records for at least 1 trait and 1,288 to 1,920 cows with records for both traits. For Holstein, data from the 5 samples included 5,606 to 9,432 BCS records (7,351 on average), 5,205 to 11,299 reproduction records (7,682 on average), and 6,011 to 13,602 cows with at least 1 record ( 8,812 on average) depending on the sample and on the trait. The number of cows with both records ranged between 5,212 and 7,321 . This number of records was about $20 \%$ of the total number of cows. The number of herds was 108 for the Ayrshire data set, 1,816 for the complete Holstein data set, and 342 for the Holstein data set that was used for variance component estimation. Finally, pedigree data were extracted from the database used for the official Canadian genetic evaluations and were limited to animals born after 1985 .

\section{Models and Genetic Parameter Estimation}

The models were developed based on the official genetic evaluation models for reproduction traits, initially developed by Jamrozik et al. (2005) and then updated by the Canadian Dairy Network (Interbull, 2009). For Ayrshire, six 2-trait (BCS and each of the 6 reproduction traits) models were run. For Holstein, the six 2 -trait models were run for each of the 5 samples. The effects used to model CTFS, FSTC, and DO were the same.

The following model was used:

$$
\mathbf{y}=\mathbf{X} \boldsymbol{\beta}+\mathbf{Z}_{1} \mathbf{h}+\mathbf{Z}_{2} \mathbf{p}_{\mathbf{m}}+\mathbf{Z}_{3} \mathbf{p}_{\mathbf{d}}+\mathbf{Z}_{4} \mathbf{a}+\mathbf{Z}_{5} \mathbf{d}+\mathbf{e},
$$

where $\mathbf{y}$ was the vector of observations for BCS and one of the reproduction traits; $\boldsymbol{\beta}$ was the vector of the following fixed effects: for CTFS, FSTC and DO, 1) class of 2 yr of birth $\times$ season of birth, 2) age at calving $\times$ season of calving; for NRR, 1) class of $2 \mathrm{yr}$ of birth $\times$ season of birth, 2) age at calving $\times$ season of first service; for CE and CS, 1) class of 2 yr of birth $\times$ season of birth, 2) age at calving $\times$ season of calving $\times$ sex of calf; for BCS, 1) class of 2 yr of calving $\times$ season of calving, 2) age at calving $\times$ class of 14 DIM; for CTFS, DO, FSTC, CE, and CS, $\mathbf{h}$ was the vector

Table 2. Descriptive statistics of the edited Holstein complete data set and the data set used for parameter estimation (VCE data set) for each model: BCS with one of the following traits: calving to first service (CTFS), first service to conception (FSTC), days open (DO), 56-d nonreturn rate at first insemination (NRR), calving ease (CE), and calf survival (CS)

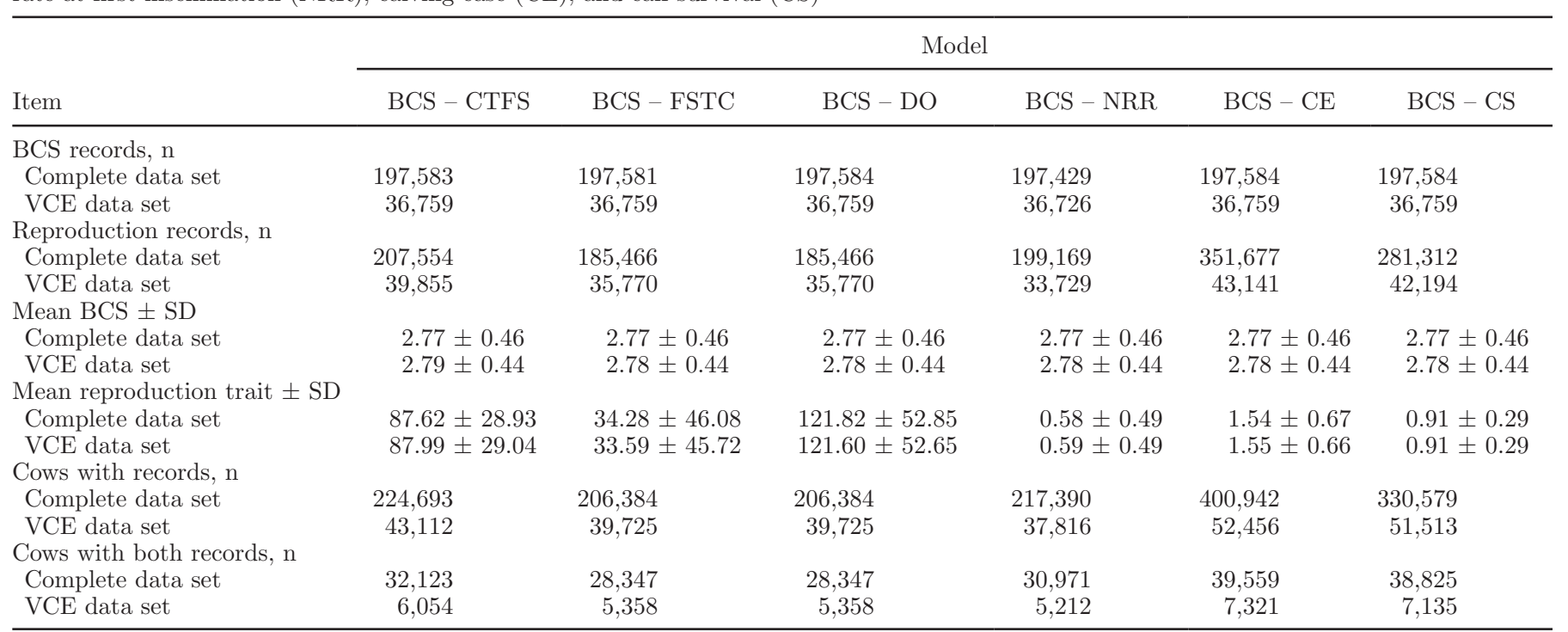


for the following random effect: 1 ) herd $\times$ class of $2 \mathrm{yr}$ of birth; for NRR, $\mathbf{h}$ was the vector of the following random effects: 1 ) herd $\times$ class of 2 yr of birth, 2) AI technician $\times$ class of 2 yr of first service, 3) service sire $\times$ class of 2 yr of first service; and for BCS, $\mathbf{h}$ was the vector of random regression coefficients for the effect of herd $\times$ class of 2 yr of calving; $\mathbf{p}_{\mathrm{m}}$ was the vector of random regression coefficients for permanent environmental effect for BCS, the vector of the random environmental effect for fertility traits, and the vector of the random environmental maternal effect for calving traits; $\mathbf{p}_{\mathbf{d}}$ was the vector of the random direct environmental effect for calving traits; $\mathbf{a}$ was the vector of random regression coefficients for additive genetic effect for BCS, the vector of the random additive genetic effects for fertility traits, and the vector of maternal (cow) genetic effects for calving traits; $\mathbf{d}$ was the vector of direct (calf) genetic effects for calving traits; e was a vector of residuals; and $\mathbf{X}$ and $\mathbf{Z}_{\mathbf{i}}(i=1,5)$ were incidence matrices assigning observations to effects.

Inasmuch as BCS is a longitudinal trait over the lactation, calving date rather than birth date was chosen to determine environmental effects for BCS. Because the information was not available, an effect accounting for BCS assessors was not included in the model. Four groups for age at calving were defined as $<24 \mathrm{mo}$, from 24 to $26 \mathrm{mo}$, from 27 to $28 \mathrm{mo}$ and $>28$ mo. Four seasons of birth or calving were defined as December to February, March to May, June to August, and September to November. Regression curves were modeled using Legendre polynomials of order 2 (quadratic); this order was chosen first considering the number of available BCS records per first-parity cow, and second based on preliminary results that showed that the model tended to be overparameterized using higher order Legendre polynomials. Moreover, other studies such as Berry et al. (2003b) presented little advantage of using Legendre polynomials of order 3 instead of order 2 .

For the analyses of fertility traits, the covariance matrices for environmental and additive genetic effects combined the variance for the fertility trait $\left(\sigma_{f}^{2}\right)$, the (co)variances for random regression components for BCS (e.g., $\sigma_{b c s L 0}^{2}, \sigma_{b c s L 0, b c s L 2}$ ) and the covariance between the fertility trait and random regression components for BCS (e.g., $\sigma_{f, b c s L 0}$ ). The (co)variance matrix had the following structure:

$$
\left[\begin{array}{cccc}
\sigma_{f}^{2} & \sigma_{f, b c s L 0} & \cdots & \sigma_{f, b c s L 2} \\
\sigma_{f, b c s L 0} & \sigma_{b c s L 0}^{2} & \cdots & \sigma_{b c s L 0, b c s L 2} \\
\cdots & \cdots & \cdots & \cdots \\
\sigma_{f, b c s L 2} & \sigma_{b c s L 0, b c s L 2} & \cdots & \sigma_{b c s L 2}^{2}
\end{array}\right] .
$$

For calving traits, the covariance matrices for genetic and environmental effects combined the variance for the maternal effect of calving trait $\left(\sigma_{c m}^{2}\right)$, the variance for the direct effect of calving trait $\left(\sigma_{c d}^{2}\right)$, the (co)variances for random regression components for BCS (e.g., $\left.\sigma_{b c s L 0}^{2}, \sigma_{b c s L 0, b c s L 2}\right)$ and the covariance between maternal or direct effect of calving trait and random regression components for BCS (e.g., $\left.\sigma_{c m, b c s L 0}, \sigma_{c d, b c s L 1}\right)$. Covariance between maternal and direct genetic effects was assumed to be zero, as in the official evaluation run by Canadian Dairy Network. The covariance environmental and genetic matrices had the following structure:

$$
\left[\begin{array}{ccccc}
\sigma_{c m}^{2} & \sigma_{c m, b c s L 0} & \sigma_{c m, b c s L 1} & \cdots & 0 \\
\sigma_{c m, b c s L 0} & \sigma_{b c s L 0}^{2} & \sigma_{b c s L 0, b c s L 1} & \cdots & \sigma_{c d, b c s L 0} \\
\sigma_{c m, b c s L 1} & \sigma_{b c s L 0, b c s L 1} & \sigma_{b c s L 1}^{2} & \cdots & \sigma_{c d, b c s L 1} \\
\cdots & \cdots & \cdots & \cdots & \cdots \\
0 & \sigma_{c d, b c s L 0} & \sigma_{c d, b c s L 1} & \cdots & \sigma_{c d}^{2}
\end{array}\right] .
$$

Including environmental covariance between reproduction traits and BCS in the model allowed for the nongenetic link between BCS and those traits to be taken into account across the lactation. It also avoided an overestimation of the genetic correlations between BCS and reproduction traits. Random effects were assumed to be normally distributed and residual variances were assumed to be independent and constant over the lactation. (Co)variance estimation was performed using expectation maximization (EM)-REML (Misztal, 2007) on the whole population of Ayrshire cows and on the 5 random samples of complete herds for Holstein. The 5 sets of variance components for Holstein were averaged afterward. For both breeds, variance components for BCS over the lactation were averaged across the six 2-trait analyses; standard errors of genetic variances were assumed to be the standard deviation of genetic variances across analyses. For Ayrshire reproductive traits, standard errors of genetic variances were estimated by running average information (AI)-REML for 1 round, using the final estimates given by EM-REML as priors. For Holstein reproductive traits, standard errors of genetic variance were assumed to be the standard deviation of genetic variances across the 5 samples. Daily heritability of BCS was defined as the ratio of genetic variance to the sum of all random effects variances for each DIM from 5 to 335 d; daily BCS heritabilities were then averaged across the 6 separate 2 -trait analyses within each breed. Finally, the average daily BCS heritability was defined as the average across the entire lactation. The genetic correlations among BCS at different stages of lactation were also computed within 


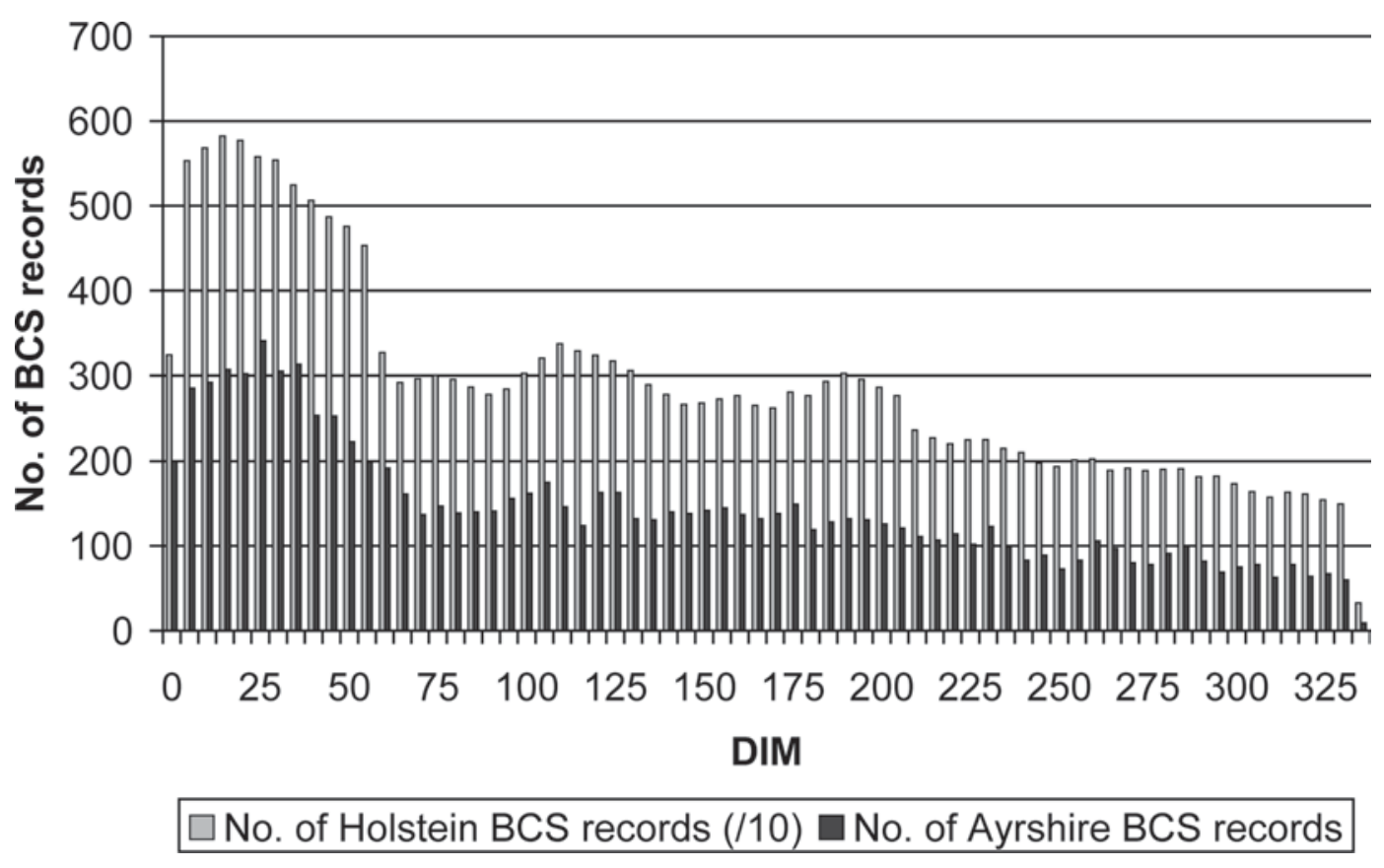

Figure 1. Number of BCS records for first-lactation Holstein cows (/10) and Ayrshire cows across DIM.

each breed for the six 2-trait models and were then averaged. Heritabilities for reproduction traits were defined as the ratio of genetic variance to the sum of all random effect variances. Genetic correlations across the lactation between BCS and reproduction traits were obtained as the diagonal of $\mathbf{Q} \mathbf{G} \mathbf{Q}^{\prime}$, where $\mathbf{G}$ represents the covariance matrix of the genetic effect and $\mathbf{Q}$ is a $23 \times 3$ matrix containing Legendre polynomials coefficients computed for DIM $5,20,35, \ldots, 320$, and 335 . Phenotypic correlations were computed using the same method, but replacing $\mathbf{G}$ by $\mathbf{T}$, which represented the total covariance matrix and was obtained as the sum of the (co)variances for all random effects including residuals.

\section{RESULTS AND DISCUSSION}

\section{Data}

Descriptive statistics are presented in Table 1 for the complete edited Ayrshire data set. Table 2 contains descriptive statistics for the complete edited Holstein data set and the data set used for variance component estimation, which included all 5 samples. The number of available BCS and reproduction data was much lower for Ayrshire than for Holstein cows. The Holstein breed is more widely used in Canada for dairy production (constituting up to $90 \%$ of the dairy cows). Ayrshire is the second most common dairy breed, representing about $3 \%$ of Canadian dairy livestock. Figure 1 indicates the number of Holstein and Ayrshire BCS records over the lactation. On average, BCS was recorded more frequently at the beginning of the lactation than at the end. Indeed, BCS at the beginning of the lactation as well as BCS loss between calving and milk yield peak are more useful for management purposes (e.g., to indicate when to inseminate) than BCS recorded at later days in milk. For both breeds, about $60 \%$ of the BCS observations were recorded before 150 DIM.

On average, BCS was slightly greater for Ayrshire (2.87 units) than for Holstein cows (2.77 units) (Table 1 and 2). This trend was also observed over the lactation (Figure 2). Moreover, the postpartum BCS loss seemed to be slightly greater for Holstein than for Ayrshire cows. For both breeds, the BCS level decreased in the first part of the lactation and was the lowest at about 60 DIM; then, BCS level increased gradually until 335 DIM. On average, fertility was similar in both breeds (Table 1 and 2). Mean DO was close to 120 d. However, Ayrshire cattle seemed to have less calving difficulty than Holstein cattle. For Holstein cows, means and standard deviation for all the traits were practically the same between the complete data set and the data set used for variance component estimation. The sample data set can therefore be considered representative of the complete data set.

\section{Variance Components, Heritabilities, and Genetic Correlations Among BCS}

Variance components of BCS across lactation are presented in Figure 3. For both breeds, genetic variance 


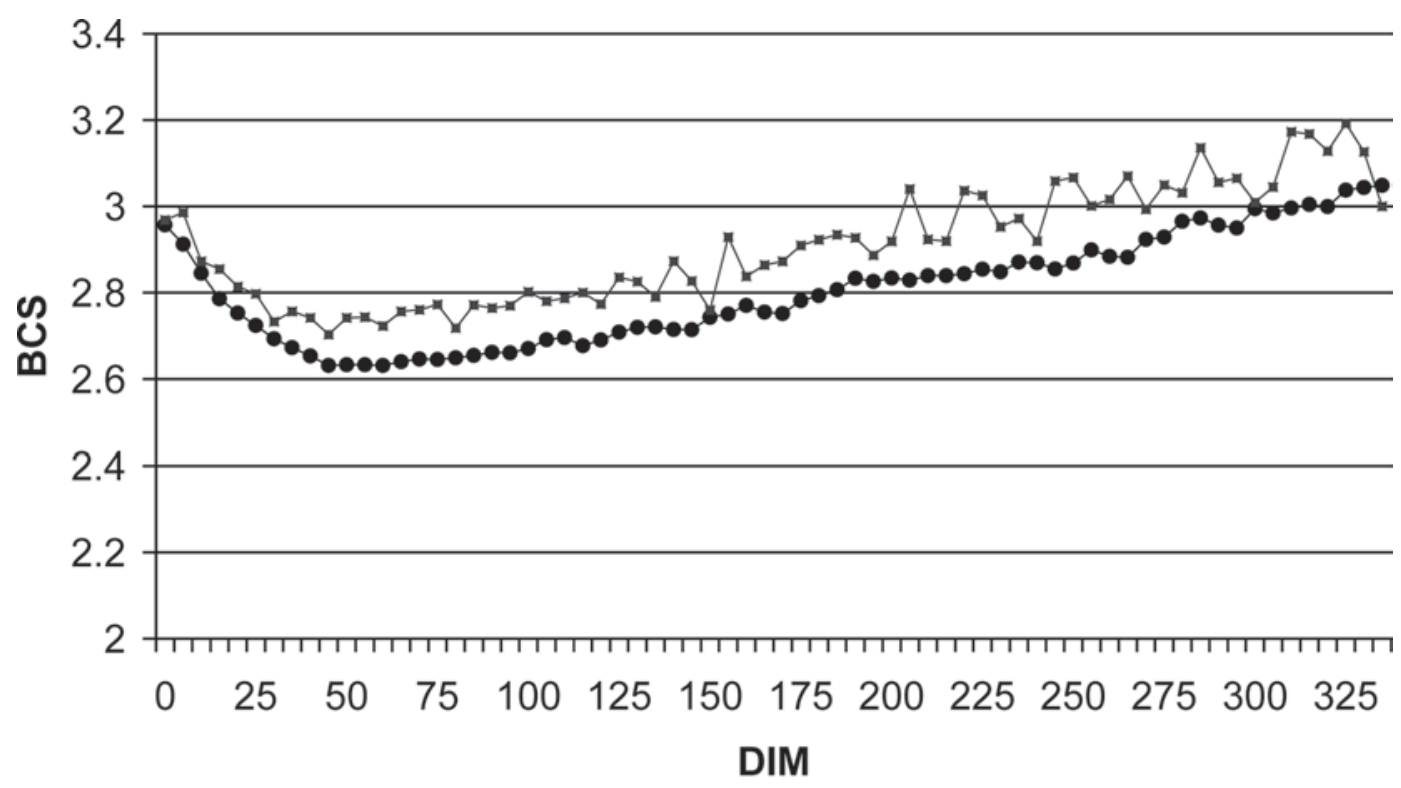

- Holstein $\rightarrow$ Ayrshire

Figure 2. Trend (daily means) of BCS records for first-lactation Holstein and Ayrshire cows across DIM.

was the lowest variance across lactation and increased with increasing DIM. Variance for the herd $\times$ class of 2 yr of calving effect was largest at the extremities of the curve. Genetic variances and their standard errors are presented in Table 3 for BCS and in Table 4 for reproduction traits. Because variance component estimation was undertaken on the whole population of Ayrshire but only on 5 independent samples for Holstein, standard errors were generally smaller for Ayrshire. Daily heritabilities for BCS in first lactation for each breed are presented in Figure 4. For Ayrshire, heritability estimates over the lactation ranged between 0.08 and 0.24 and increased with DIM. For Holstein, BCS heritability was the smallest at early lactation (0.07 at 5 DIM) and the largest in mid lactation (0.17 at 215 DIM). This result is in agreement with the literature, which indicated that BCS heritabilities tended to be larger in mid to late lactation (Koenen et al., 2001; Berry et al., 2003b). The average daily heritability, obtained as the average of the daily heritabilities across the entire lactation, was about 0.13 for both breeds (Table 5). These heritabilities were generally lower than estimates from the literature obtained from various data sets (Holstein or other breeds; one or several BCS records throughout the cow's lifetime; 5- or 9-point scale; different systems of production) using various models (random regression vs. multivariate; animal vs. sire) with estimates ranging between 0.27 and 0.36 (Gallo et al., 2001), between 0.28 and 0.37 (Koenen et al., 2001), between 0.29 and 0.43 (Berry et al., 2003a), and between 0.23 and 0.32 (Pryce and Harris, 2006). Some suggestions could be put forward to explain the relatively low heritability estimates of this study. First, BCS is a subjective measure and, in the current study, was assessed by field staff or producers. For most of the studies cited above, BCS was taken by trained individuals who used similar scoring procedures (classifiers or personnel of research center). The recording was therefore expected to be more homogeneous among herds and BCS evaluators than in the current study. This fact could explain the large proportion of the total variance explained by the herd $\times$ class of $2 \mathrm{yr}$ of calving effect (35\%), whereas the importance of the other effects was (in decreasing order): residual $(27 \%)$, permanent environment (24\%), and genetic (14\%) (Figure 3). Similarly, Koenen et al. (2001) found that random herd $\times$ visit effect had a significant influence (10 to $15 \%$ of the phenotypic variation) on heifers' BCS. Dechow et al. (2001) studied the heritability of BCS from producer- and consultant-recorded data and indicated estimates similar to those presented in this study: from 0.09 at dry-off to 0.15 at postpartum in first lactation. Further studies are therefore needed to verify if BCS at classification and BCS recorded by producer and consultant could be considered the same trait. Treating BCS data from both systems as the same trait would require the inclusion of a correction for BCS evaluator in the model, the conversion of BCS data from the difference sources to the same scale, and a strong true genetic correlation between both BCS recordings. 
Table 3. Genetic variances $(\times 100)$ and their standard errors $(\times 100)$ of the constant (i0), the linear (i1), and the quadratic (i2) Legendre coefficient of BCS

\begin{tabular}{lcccccccc}
\hline & \multicolumn{3}{c}{ Ayrshire } & & & \multicolumn{3}{c}{ Holstein } \\
\cline { 2 - 4 } \cline { 6 - 8 } Trait & i0 & i1 & i2 & & i0 & i1 & i2 \\
\hline BCS & $1.98 \pm 0.04$ & $0.20 \pm 0.01$ & $0.02 \pm 0.04$ & & $2.27 \pm 0.61$ & $0.23 \pm 0.08$ & $0.09 \pm 0.03$ \\
\hline
\end{tabular}

${ }^{1}$ Genetic variances were averaged across the six 2-trait analyses; standard errors of genetic variances were assumed to be the standard deviation of genetic variances across analyses.

Correlations between BCS observations at different stages of lactation are shown in Table 6. As expected, correlations decreased with increasing interval between days. For Ayrshire, genetic correlations remained above 0.70 over the lactation. For Holstein, BCS collected at 50 DIM was closely linked with BCS at 5 DIM and at 150 DIM, but the correlation between BCS at 5 DIM and BCS at 150 DIM was 0.58; BCS levels before and after mean DIM at nadir were positively but not strongly related, indicating that they might be determined by different biological processes under genetic control. Those correlations were generally smaller than in previous research, which presented genetic correlations among BCS ranging between 0.68 and 0.99 (Dechow et al., 2001; Gallo et al., 2001; Koenen et al., 2001).

Heritabilities for reproduction traits for both breeds in first lactation are presented in Table 5. They ranged between 0.006 and 0.059 depending on the breed and trait. Binary traits (NRR and CS) tended to have lower estimates. Heritability estimates of this study were smaller than in the study of Jamrozik et al. (2005), who provided the most recent estimates for Canadian Holstein cows. Several assumptions could be put forward to explain these differences. First, high standard errors are generally observed on estimates for reproduction traits. As presented in Table 4, standard errors of genetic variances were relatively high for those traits. Second, environmental variance was linked to BCS in the models of this study. Finally, the estimates used in Jamrozik et al. (2005) derived benefit from the use of a multivariate model, which included 16 reproductive traits.

\section{Genetic Correlations Between BCS and Fertility Traits}

Genetic correlations between BCS and fertility traits are presented in Figure 5 for Ayrshire and Figure 6

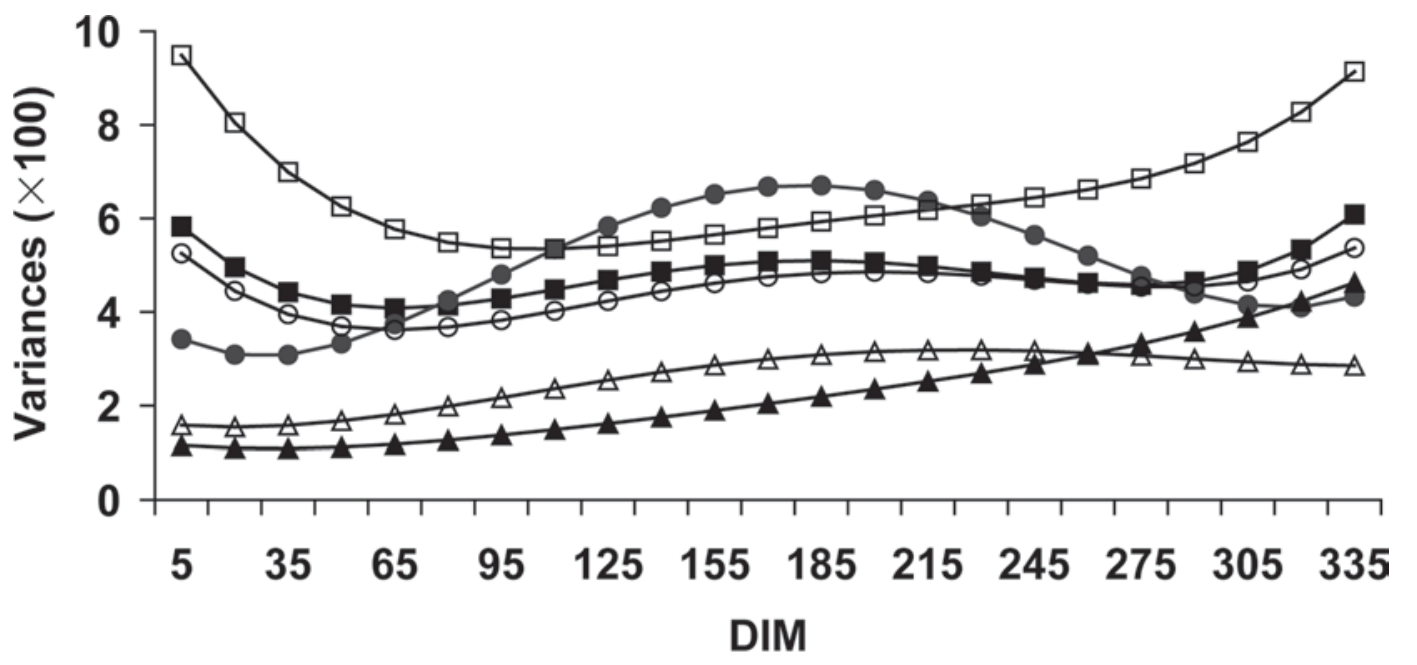

$\begin{array}{ll}- \text { - Herd x } 2 \text { years of calving (AY) } & - \text { - Permanent environment (AY) } \\ - \text { Additive genetic (AY) } & \square \text { Herd x } 2 \text { years of calving (HO) } \\ - \text { Permanent environment (HO) } & \triangle \text { Additive genetic (HO) }\end{array}$

Figure 3. Variance components (averaged for each breed across the six 2-trait analyses) of BCS for first-parity Ayrshire (AY) and Holstein (HO) cows across DIM. 
Table 4. Maternal and direct genetic variances and their standard errors in Ayrshire and Holstein breeds for the following traits: calving to first service (CTFS), first service to conception (FSTC), days open (DO), 56-d nonreturn rate at first insemination (NRR), calving ease $(\mathrm{CE})$, and calf survival $(\mathrm{CS})^{1}$

\begin{tabular}{|c|c|c|c|c|}
\hline \multirow[b]{2}{*}{ Trait } & \multicolumn{2}{|c|}{ Ayrshire } & \multicolumn{2}{|c|}{ Holstein } \\
\hline & Maternal & Direct & Maternal & Direct \\
\hline CTFS & $15.81 \pm 0.14$ & & $37.31 \pm 7.43$ & \\
\hline FSTC & $23.97 \pm 0.22$ & & $54.32 \pm 17.49$ & \\
\hline DO & $108.80 \pm 1.00$ & & $106.76 \pm 56.48$ & \\
\hline NRR & $0.49 \pm 0.00$ & & $0.29 \pm 0.07$ & \\
\hline $\mathrm{CE}$ & $0.53 \pm 0.00$ & $0.08 \pm 0.00$ & $2.28 \pm 0.41$ & $1.72 \pm 1.14$ \\
\hline $\mathrm{CS}$ & $0.04 \pm 0.00$ & $0.06 \pm 0.00$ & $0.26 \pm 0.22$ & $0.11 \pm 0.10$ \\
\hline
\end{tabular}

${ }^{1}$ For NRR, CE, and CS, variances and standard errors are multiplied by 100 . Genetic variances were averaged across analyses. For Ayrshire, standard errors of genetic variances have been estimated running average information-REML. For Holstein, standards errors of genetic variance have been assumed to be the standard deviation of genetic variances across the 5 samples.

for Holstein first-parity cows. Phenotypic correlations are presented in Table 7 for Ayrshire and Table 8 for Holstein. For both breeds, genetic correlations were negative for interval traits (CTFS, FSTC, and DO) and positive for NRR, suggesting a favorable genetic relationship between BCS and fertility. For Ayrshire, genetic correlations between BCS and interval traits were moderate to strong and did not change considerably over the lactation; they ranged between -0.77 for DO at 335 DIM and -0.58 for FSTC at 5 DIM. The genetic correlation between BCS and NRR ranged from 0.16 and 0.24. For Holstein, genetic correlations between BCS and interval traits were smaller compared with Ayrshire estimates. Between BCS and FSTC and between BCS and DO, the weakest correlation occurred in early lactation and was larger in mid and late lactation. Specifically, genetic correlations ranged from -0.19 around 200 DIM to -0.03 at 5 DIM between BCS and FSTC and from -0.31 at 200 DIM to -0.14 at 5 DIM between BCS and DO. Between BCS and CTFS, the largest correlation occurred at 50 DIM and was -0.27 . The genetic correlation between BCS and NRR ranged between 0.45 and 0.54. The phenotypic relationships between BCS and fertility traits were not as strong as the genetic relationships. The range of phenotypic correlations was -0.17 to -0.01 . Furthermore, the sign of correlation (positive or negative) was the same for phenotypic and genetic correlations.

In first-parity Holstein cows, average CTFS and DO were 88 and $122 \mathrm{~d}$, respectively ( 87 and $120 \mathrm{~d}$ in Ayrshire, respectively). Therefore, the correlations presented above suggest that a genetically low BCS in early lactation was associated with increased number of days when the cow was not pregnant and a decreased chance for the cow to be pregnant at first service. From a phenotypic point of view, dairy cows enter a negative energy state in early lactation in which they mobilize fat stores to meet the increased energy requirements of milk production. This mobilization of body reserves, represented by a loss of BCS, has been associated with delays in the onset of normal ovarian activity (limiting the number of estrus cycles before breeding) and a reduced conception rate (Butler and Smith, 1989). Furthermore, van Straten et al. (2009) indicated that the amount of body fat available for mobilization between 40 to 60 DIM was more informative as an indicator for the extent of adaptation to negative energy balance than the amount of body fat lost from calving to this period and was associated with extended FSTC. From a genetic point of view, these results indicate that cows that were genetically low for BCS may not have been able to maintain energy levels sufficient to activate

Table 5. Heritabilities of BCS, calving to first service (CTFS), first service to conception (FSTC), days open (DO), 56-d nonreturn rate at first insemination (NRR), maternal and direct calving ease (CEm and CEd, respectively), and maternal and direct calf survival (CSm and CSd, respectively) estimated for Ayrshires and Holsteins

\begin{tabular}{lccccccccc}
\hline & \multicolumn{10}{c}{ Trait } \\
\cline { 2 - 9 } Breed & BCS $^{1}$ & CTFS & FSTC & DO & NRR & CEm & CEd & CSm & CSd \\
\hline Ayrshire & 0.133 & 0.020 & 0.013 & 0.044 & 0.020 & 0.016 & 0.059 & 0.006 & 0.011 \\
Holstein & 0.137 & 0.044 & 0.026 & 0.039 & 0.012 & 0.053 & 0.040 & 0.031 & 0.013 \\
\hline
\end{tabular}

${ }^{1}$ Heritability for BCS was obtained as the average of daily heritabilities over the lactation obtained as the average across the six 2-trait analyses. 


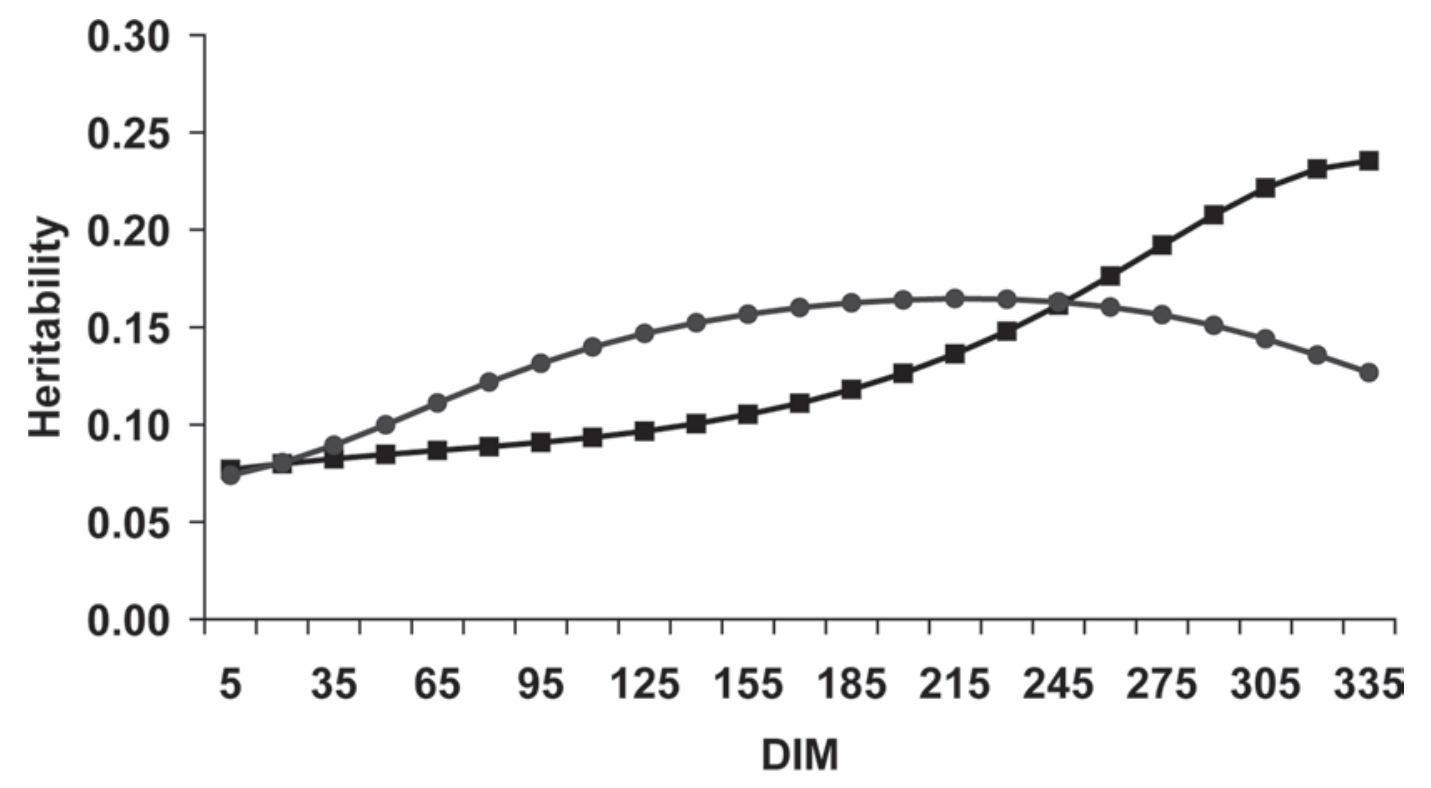

$\rightarrow$ - Ayrshire $\rightarrow-$ Holstein

Figure 4. Daily heritabilities (averaged for each breed across the six 2-trait analyses) of BCS for first-parity Ayrshire and Holstein cows across DIM.

ovarian function or display estrus. These types of cows are likely inseminated for the first time at a later date because of a delay in the onset of ovulation or estrus (Dechow et al., 2001) and would likely conceive later as well. The estimated correlations in this study are in the range of those reported in previous studies. Dechow et al. (2001) reported a genetic correlation of -0.12 between BCS at calving and CTFS for first-parity Holstein cows. Berry et al. (2003b) estimated genetic correlations between BCS and CTFS that varied slightly

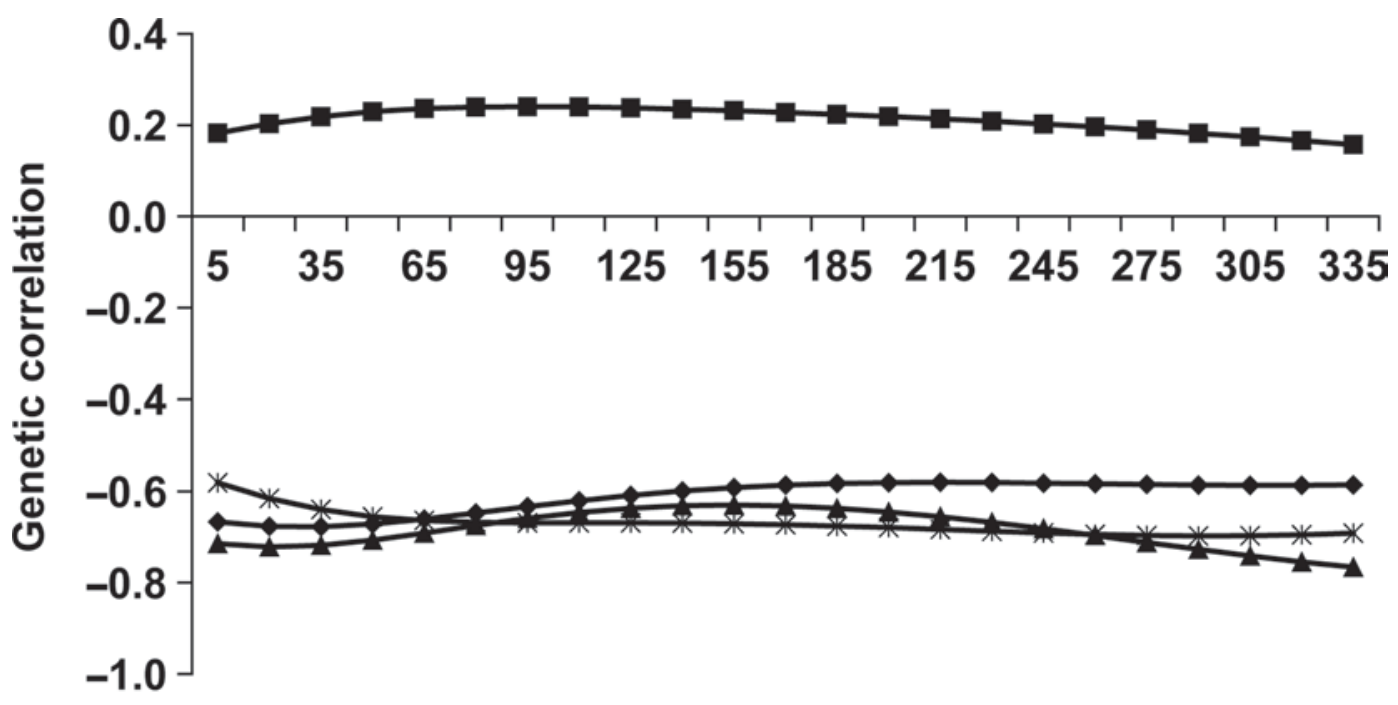

DIM

\section{BCS-CTFS *BCS-FSTC $\leftarrow$ BCS-DO $\rightarrow$-BCS-NRR}

Figure 5. Genetic correlations between BCS and fertility traits: calving to first service (CTFS), first service to conception (FSTC), days open (DO), and 56-d nonreturn rate at first insemination (NRR) for first-parity Ayrshire cows across DIM. 
Table 6. Genetic correlations over DIM among first-parity BCS for Ayrshire (above diagonal) and Holstein (below diagonal)

\begin{tabular}{lccccc}
\hline & \multicolumn{5}{c}{ DIM } \\
\cline { 2 - 6 } DIM & 5 & 50 & 150 & 250 & 335 \\
\hline 5 & & 0.93 & 0.71 & 0.70 & 0.74 \\
50 & 0.90 & & 0.91 & 0.88 & 0.83 \\
150 & 0.58 & 0.88 & & 0.97 & 0.87 \\
250 & 0.46 & 0.78 & 0.97 & & 0.95 \\
335 & 0.43 & 0.65 & 0.81 & 0.92 & \\
\hline
\end{tabular}

around -0.35 during the first 100 DIM for multiparous Holstein cows using a random regression model. Additionally, Veerkamp et al. (2001) estimated genetic correlations for first-parity cows by using a random regression model and found stronger estimates, ranging between -0.60 and -0.50 , during the first $100 \mathrm{~d}$ of the lactation.

As shown in Figures 5 and 6 , the genetic correlations between BCS and fertility traits were generally larger in mid and late lactation than in the immediate postpartum period. Correlations between BCS in mid and late lactation with fertility traits could be more difficult to interpret as the BCS recording occurs after the fertility event (either first service or conception), and the causal relationship is not as clear as it is for BCS in early lactation. According to Reksen et al. (2002), greater BCS from wk 13 to 15 after calving for first-parity Norwegian dairy cows was associated with early onset of luteal function (defined as the appearance of a progesterone concentration $>5 \mathrm{ng} / \mathrm{mL}$ in the $24 \mathrm{~d}$ after calving), which would suggest better reproductive performance. Berry et al. (2003b) reported stronger genetic correlations between BCS and CTFS in mid and late lactation $(-0.47$ at around 250 DIM). Meanwhile, Veerkamp et al. (2001) showed that BCS in early lactation was more strongly correlated with CTFS. Therefore, although BCS during the postpartum period reflects the extent of the negative energy balance of the cow, BCS in mid and late lactation might indicate the ability of the cow to recover body reserves after this critical period and could therefore be genetically related to reproductive performance. Berry et al. (2003b) suggested that the maximum genetic gain in fertility from indirect selection on BCS should be based on measurements taken in mid lactation when the genetic variance for BCS is largest and the correlations between BCS and fertility traits are the strongest.

Overall, genetic correlations between fertility and BCS were generally stronger for Ayrshire than for Holstein. Historically, the Canadian Ayrshire in North America has been highly selected for dairy form and has a lower body weight than Holstein. This selection might have reinforced the relationship between BCS and fertility.

\section{Genetic Correlations Between BCS and Calving Traits}

Although phenotypic and genetic correlations between BCS and fertility traits have often been studied,

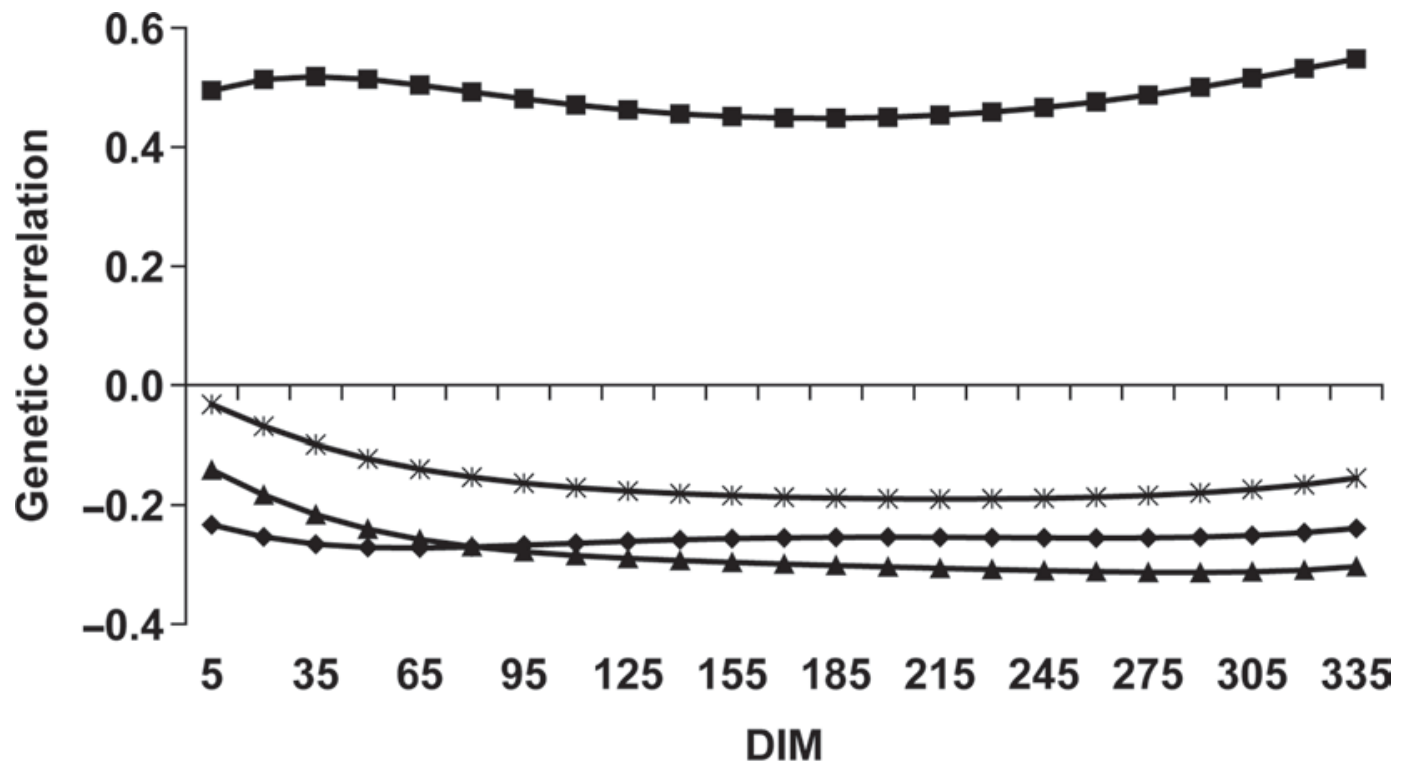

BCS-CTFS *-BCS-FSTC $\leftarrow$ BCS-DO $\#$-BCS-NRR

Figure 6. Genetic correlations between BCS and fertility traits: calving to first service (CTFS), first service to conception (FSTC), days open (DO), and 56-d nonreturn rate at first insemination (NRR) for first-parity Holstein cows across DIM. 
Table 7. Phenotypic correlations between BCS and the reproduction traits calving to first service (CTFS), first service to conception (FSTC), days open (DO), 56-d nonreturn rate at first insemination (NRR), maternal and direct calving ease (CEm and CEd, respectively), and maternal and direct calf survival (CSm and CSd, respectively) for first-parity Ayrshire cows across DIM

\begin{tabular}{|c|c|c|c|c|c|}
\hline \multirow[b]{2}{*}{ Model } & \multicolumn{5}{|c|}{ DIM } \\
\hline & 5 & 50 & 100 & 200 & 335 \\
\hline BCS - CTFS & -0.08 & -0.10 & -0.10 & -0.09 & -0.06 \\
\hline BCS - FSTC & -0.04 & -0.05 & -0.06 & -0.07 & -0.07 \\
\hline BCS - DO & -0.09 & -0.09 & -0.07 & -0.09 & -0.17 \\
\hline BCS - NRR & 0.02 & 0.03 & 0.03 & 0.03 & 0.01 \\
\hline BCS - CEm & 0.01 & 0.01 & 0.01 & 0.01 & 0.04 \\
\hline $\mathrm{BCS}-\mathrm{CEd}$ & -0.04 & -0.01 & 0.02 & 0.04 & 0.00 \\
\hline $\mathrm{BCS}-\mathrm{CSm}$ & -0.05 & -0.03 & -0.01 & -0.01 & -0.05 \\
\hline $\mathrm{BCS}-\mathrm{CSd}$ & -0.03 & 0.01 & 0.04 & 0.08 & 0.07 \\
\hline
\end{tabular}

few authors have investigated the association between BCS and calving traits. Moreover, to our knowledge, genetic relationships between BCS and calving traits have not been reported. Genetic correlations between BCS and calving traits are presented in Figure 7 for Ayrshire and in Figure 8 for Holstein first-parity cows. Phenotypic correlations are presented in Table 7 for Ayrshire and Table 8 for Holstein. For both breeds, the genetic correlations between BCS and maternal CE (CEm) were mostly positive and ranged from 0.13 to 0.31 for Ayrshire and from -0.02 to 0.21 for Holstein. The strongest correlations occurred at calving and decreased throughout the lactation. Genetic correlations between BCS and direct CE (CEd) were mostly negative for both Ayrshire and Holstein and were weaker with increasing DIM. The range was -0.31 to -0.12 for Ayrshire and -0.31 to 0.05 for Holstein. For Ayrshire, genetic correlations between BCS and maternal CS (CSm) as well as direct CS (CSd) were positive and were stronger in early stages of lactation. For Holstein, the genetic relationship between BCS and CSm was positive and varied slightly around 0.16 . The genetic correlation between BCS and CSd was generally positive and was strongest in mid lactation. Phenotypic cor- relations for calving traits were close to zero for most of the traits in both breeds.

Because calving is the starting point of the lactation, correlations presented in Figures 7 and 8 indicate the causal relationship of dystocia and calf survival on BCS over the lactation. However, considering that BCS at 5 DIM represented the BCS level at calving, these results indicated that a genetically high BCS at calving 1) increased the chance of the cow to have dystocia (CEm); 2) increased the chance of the calf to be born easily (CEd); 3) increased the chance of the cow to have a calf that survived (CSm); and 4) increased the chance of the calf to survive (CSd) for Ayrshire but not for Holstein (for which the genetic correlation between CSd and BCS was close to zero and negative at 5 DIM). The positive correlation between BCS around calving and the maternal effect for calving ease was in agreement with previous studies that investigated the phenotypic effect of BCS on calving performance traits. Indeed, animals carrying excessive body condition resulting in intrapelvic fat deposition and a reduction in pelvic area (especially for first-lactation heifers) are more likely to develop dystocia (Gearhart et al., 1990). Chassagne et al. (1999) indicated that having a BCS >4 (on a

Table 8. Phenotypic correlations between BCS and the reproduction traits calving to first service (CTFS), first service to conception (FSTC), days open (DO), 56-d nonreturn rate at first insemination (NRR), maternal and direct calving ease (CEm and CEd, respectively), and maternal and direct calf survival (CSm and CSd, respectively) for first-parity Holstein cows across DIM

\begin{tabular}{|c|c|c|c|c|c|}
\hline \multirow[b]{2}{*}{ Model } & \multicolumn{5}{|c|}{ DIM } \\
\hline & 5 & 50 & 100 & 200 & 335 \\
\hline BCS - CTFS & -0.05 & -0.07 & -0.08 & -0.08 & -0.05 \\
\hline BCS - FSTC & -0.02 & -0.04 & -0.06 & -0.07 & -0.05 \\
\hline $\mathrm{BCS}-\mathrm{DO}$ & -0.05 & -0.08 & -0.10 & -0.11 & -0.09 \\
\hline BCS - NRR & 0.01 & 0.01 & 0.01 & 0.02 & 0.05 \\
\hline BCS - CEm & 0.00 & 0.00 & 0.00 & -0.01 & 0.00 \\
\hline BCS - CEd & -0.04 & -0.02 & 0.00 & 0.03 & 0.03 \\
\hline $\mathrm{BCS}-\mathrm{CSm}$ & 0.02 & 0.00 & -0.01 & -0.02 & 0.01 \\
\hline BCS - CSd & -0.07 & -0.03 & 0.01 & 0.08 & 0.11 \\
\hline
\end{tabular}




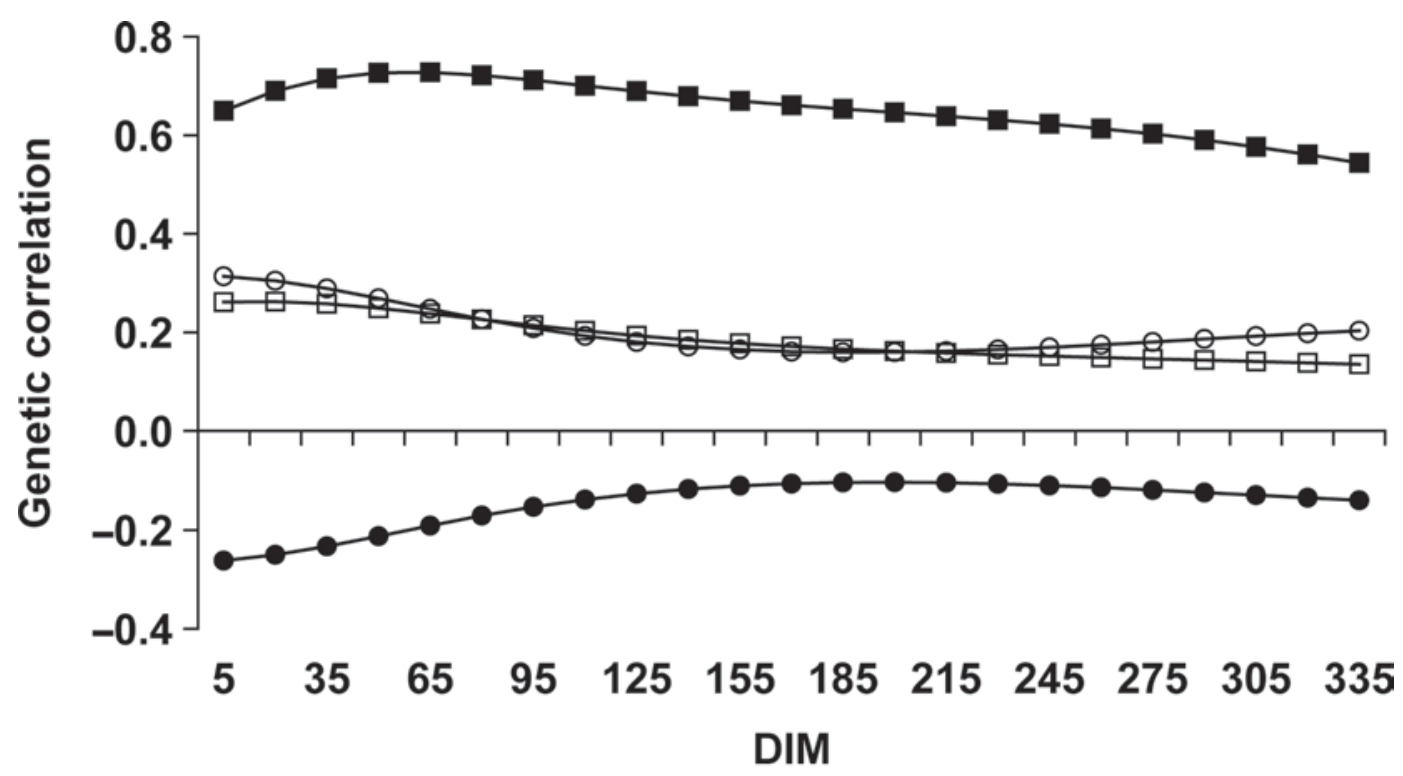

๑ BCS-CEm $\rightarrow$ BCS-CEd $\square$ BCS-CSm - - BCS-CSd

Figure 7. Genetic correlations between BCS and calving traits: calving ease maternal (CEm) and direct (CEd) and calf survival maternal (CSm) and direct (CSd) for first-parity Ayrshire cows across DIM.

5-point scale) before calving posed a significant risk for dystocia. According to Gearhart et al. (1990), cows that developed dystocia lost more body condition during the previous dry period than those that did not develop dystocia. However, Berry et al. (2007) investigated the phenotypic relationship between BCS and dystocia and concluded that periparturient BCS did not significantly affect incidence of dystocia and stillbirth. Waltner et al. (1993) did not find any significant relationships between BCS and incidence of dystocia. Nevertheless, the very small number of overconditioned cows in these latter 2 studies might have biased the results, as Chassagne et

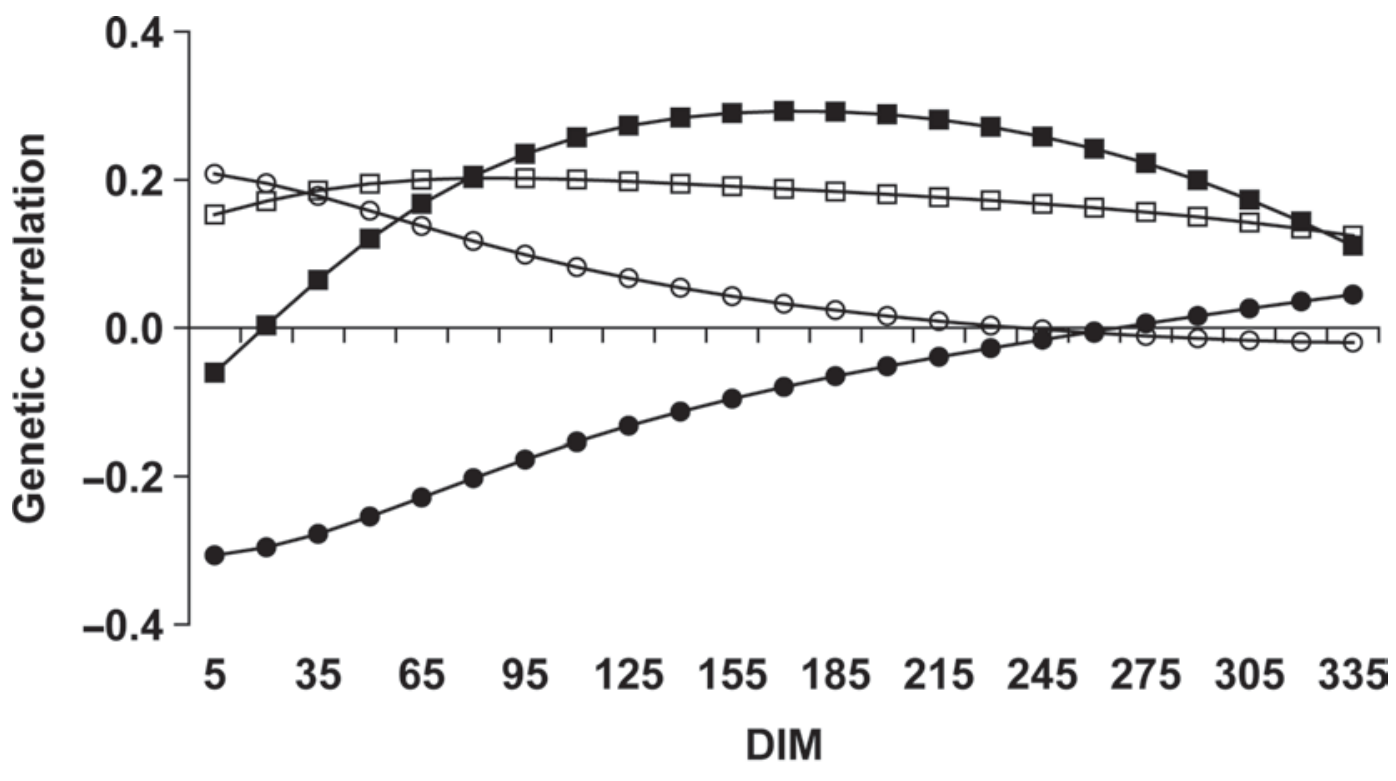

๑ BCS-CEm - BCS-CEd — BCS-CSm - - BCS-CSd

Figure 8. Genetic correlations between BCS and calving traits: calving ease maternal (CEm) and direct (CEd) and calf survival maternal $(\mathrm{CSm})$ and direct (CSd) for first-parity Holstein cows across DIM. 
al. (1999) supported the involvement of obesity in these disorders. Further studies are needed to investigate the genetic relationship between BCS during the period preceding calving and calving traits for primiparous and multiparous cows. Preliminary results realized on Canadian Ayrshire cows indicated that the genetic correlation between BCS during the $100 \mathrm{~d}$ before the second calving and CEm at second calving ranged between 0.51 at $100 \mathrm{~d}$ before calving and 0.28 at 5 DIM (Bastin et al., 2009). This result suggests that overconditioning of dry cows is detrimental to calving ease.

Concerning the genetic relationship between BCS and calving traits during the following lactation, the estimates presented in Figures 7 and 8 had the same sign (positive or negative) as for BCS at calving (except for CSd for Holstein), but generally decreased with increasing DIM. The positive genetic correlation between $\mathrm{CEm}$ and BCS during the following lactation was in contrast with the phenotypic study of Berry et al. (2007), who reported that cows that experienced dystocia lost more BCS to nadir, resulting in reduced BCS at nadir.

With the exception of the positive genetic correlation between BCS at calving and CEm, which emphasized the phenotypic relationship between fat cows around calving and dystocia supported by other researchers (Gearhart et al., 1990; Chassagne et al., 1999), genetic correlations between calving traits and BCS during the subsequent lactation were favorable. This seems to indicate that cows with a genetically high BCS 1) would have a greater chance to have a calf that survives (CSm) and 2) would transmit genes to the calf that permit an easy birth (CEd) and increased chance of survival (CSd). These last statements are supported by previous research that reported that genetically low BCS was related to less robust cows presenting impaired fertility (Dechow et al., 2001; Pryce et al., 2001) or health disorders such as mastitis (Lassen et al., 2003; Neuenschwander et al., 2009).

\section{Use of BCS in Selection Programs}

Current breeding programs tend to combine both productive and functional aspects to select high-producing and robust cows. In support of this global objective, the interest in functional traits such as BCS is increasing, especially because of its relationship with economically important traits that take an increasing weight in modern breeding objectives, such as fertility. Because fertility traits are difficult to measure, are often not readily available, and have low heritabilities, BCS can serve as predictor for estimating breeding values for fertility traits (Berry et al., 2003b).
Results of this research indicate that BCS may be a useful indicator trait in selection programs to select for or maintain better reproductive performance; BCS could therefore be included in indices for fertility or robustness but not in the breeding objective. This strategy has been suggested in previous studies. Dechow et al. (2004) showed that genetic evaluations for BCS could be used to increase the predicted transmitted ability for DO for bulls that have few daughters with direct DO observations. Furthermore, Berry et al. (2003b) indicated that BCS could be used as a predictor for EBV for fertility traits with accuracy no greater than the genetic correlation between BCS and the trait of interest. This approach could be applicable in 2 cases: when fertility data and BCS data can be simultaneously included in the selection index (Wall et al., 2003) or when fertility data may only be available after the cow has had a subsequent calving. As this study showed that heritabilities of reproduction traits were low, heritability for BCS was moderate, and the correlations between BCS and reproduction traits were generally moderate, developing selection tools based on BCS would allow indirect selection on reproduction traits.

\section{CONCLUSIONS}

Except for CEm, favorable genetic correlations were found between BCS and fertility and calving traits studied; correlations were stronger in mid lactation for fertility traits and in early lactation for calving traits. Genetic correlation trends were the same for both breeds but were generally greater for Ayrshire than for Holstein. This might reflect a different focus of selection between the breeds. A genetically high BCS in early and mid lactation for primiparous cows was associated with 1) shortened time during which the cow was not pregnant (CTFS, FSTC, DO), 2) greater chance of the cow to be pregnant at first service (NRR), 3) greater chance of the cow to have had dystocia $(\mathrm{CEm}), 4)$ greater chance for the calf to have survived (CSm), 5) greater chance for the cow to have transmitted genes to the calf that would have permitted an easy birth (CEd) and a greater chance of survival (CSd). Moreover, further studies are needed to investigate the relationships between BCS at drying and the subsequent reproductive performances. Similar studies on data from multiparous cows need to be conducted because conclusions from first parity cannot be extended to later parities.

\section{ACKNOWLEDGMENTS}

Authors are grateful to Valacta (Québec, Canada) for providing BCS data for this research. Catherine Bastin 
acknowledges the supports of National Fund for Scientific Research (Brussels, Belgium) and Wallonie-Bruxelles International (CGRI-DRI, WBI) through grants provided for scientific stay at University of Guelph (Ontario, Canada). Additional financial support of the Ministry of Agriculture of Walloon Region of Belgium (Service Public de Wallonie, Direction générale opérationnelle "Agriculture, Ressources naturelles et Environnement" (DGA-RNE), Direction du Développement et de la Vulgarisation) (Namur, Belgium) was also provided. Nicolas Gengler who is a research associate of the National Fund for Scientific Research (Brussels, Belgium) acknowledges his support. Additional support was provided through grants $2.4507 .02 \mathrm{~F}$ (2) and F.4552.05 of the National Fund for Scientific Research. The support of DairyGen Council of Canadian Dairy Network and Natural Sciences and Engineering Research Council of Canada is also acknowledged. Authors are grateful to Alain Gillon (Animal Science Unit, Gembloux AgroBio Tech, University of Liège, Belgium) as well as to Jarmila Bohmanova (Center for Genetic Improvement of Livestock, University of Guelph, Ontario, Canada) for their assistance and to L. R. Schaeffer and J. Jamrozik (Center for Genetic Improvement of Livestock, University of Guelph, Ontario, Canada) for their helpful comments and suggestions.

\section{REFERENCES}

Bastin, C., S. Loker, N. Gengler, and F. Miglior. 2009. Estimates of genetic parameters among body condition score and calving traits in first parity Canadian Ayrshire cows. Proc. 60th Annual Meeting of the European Association for Animal Production, Barcelona, Spain.

Berry, D. P., F. Buckley, P. Dillon, R. D. Evans, M. Rath, and R. F. Veerkamp. 2003a. Genetic relationships among body condition score, body weight, milk yield, and fertility in dairy cows. J. Dairy Sci. 86:2193-2204.

Berry, D. P., F. Buckley, P. Dillon, R. D. Evans, M. Rath, and R. F. Veerkamp. 2003b. Genetic parameters for body condition score, body weight, milk yield, and fertility estimated using random regression models. J. Dairy Sci. 86:3704-3717.

Berry, D. P., J. M. Lee, K. A. Macdonald, and J. R. Roche. 2007. Body condition score and body weight effects on dystocia and stillbirths and consequent effects on postcalving performance. J. Dairy Sci. 90:4201-4211.

Butler, W. R., and R. D. Smith. 1989. Interrelationships between energy balance and postpartum reproductive function in dairy cattle. J. Dairy Sci. 72:767-783.

Chassagne, M. J., J. Barnouin, and J. P. Chaconac. 1999. Risk factors for stillbirth in Holstein heifers under field conditions in France: A prospective survey. Theriogenology 51:1477-1488.

Dechow, C. D., G. W. Rogers, and J. S. Clay. 2001. Heritabilities and correlations among body condition scores, production traits, and reproductive performances. J. Dairy Sci. 84:266-275.

Dechow, C. D., G. W. Rogers, L. Klei, T. J. Lawlor, and P. M. VanRaden. 2004. Body condition scores and dairy form evaluations as indicators of days open in US Holsteins. J. Dairy Sci. 87:35343541.
Dematawewa, C. M. B., and P. J. Berger. 1997. Effect of dystocia on yield, fertility, and cow losses and an economic evaluation of dystocia scores for Holsteins. J. Dairy Sci. 80:754-761.

Edmonson, A. J., I. J. Lean, L. D. Weaver, T. Farver, and G. Webster. 1989. A body condition scoring chart for Holstein dairy cows. J. Dairy Sci. $72: 68-78$.

Gallo, L., P. Carnier, M. Cassandro, R. dal Zotto, and G. Bittante. 2001. Test-day genetic analysis of condition score and heart girth in Holstein Friesian cows. J. Dairy Sci. 84:2321-2326.

Gearhart, M. A., C. R. Curtis, H. N. Herb, R. D. Smith, C. J. Sniffen, L. E. Chase, and M. D. Cooper. 1990. Relationship of changes in condition score to cow health in Holsteins. J. Dairy Sci. 73:31323140 .

Interbull. 2009. Description of national genetic evaluation systems. http://www-interbull.slu.se/national_ges_info2/framesida-ges. htm Accessed Sep. 4, 2009.

Jamrozik, J., J. Fatehi, G. J. Kistemaker, and L. R. Schaeffer. 2005. Estimates of genetic parameters for Canadian Holstein female reproduction traits. J. Dairy Sci. 88:2199-2208.

Koenen, E. P. C., R. F. Veerkamp, P. Dobbelaar, and G. De Jong. 2001. Genetic analysis of body condition score of lactating Dutch Holstein and Red-and-White heifers. J. Dairy Sci. 84:1265-1270.

Lassen, J., M. Hansen, M. K. S. Ørensen, G. P. Aamand, L. G. Christensen, and P. Madsen. 2003. Genetic relationship between body condition score, dairy character, mastitis, and diseases other than mastitis in first parity Danish Holstein cows. J. Dairy Sci. $86: 3730-3735$.

Lucy, M. C. 2001. ADSA Foundation Scholar Award: Reproductive loss in high-producing dairy cattle: Where will it end? J. Dairy Sci. 84:1277-1293.

Meijering, A. 1984. Dystocia and stillbirth in cattle-A review of causes, relations and implications. Livest. Prod. Sci. 11:143-177.

Misztal, I. 2007. BLUPF90 family of programs. University of Georgia. http://nce.ads.uga.edu/ ignacy/numpub/blupf90/ Accessed on Dec. 2, 2007.

Neuenschwander, T. F.-O., F. Miglior, J. Jamrozik, and L. R. Schaeffer. 2009. Bivariate analyses of body condition score and health traits in Canadian Holstein cattle using a random regression model. Proc. 60th Annual Meeting of the European Association for Animal Production, Barcelona, Spain.

Pryce, J. E., M. P. Coffey, and G. Simm. 2001. The relationship between body condition score and reproductive performance. J. Dairy Sci. 88:2199-2208.

Pryce, J. E., and B. L. Harris. 2006. Genetics of body condition score in New Zealand dairy cows. J. Dairy Sci. 89:4424-4432.

Reksen, O., Ø. Havrevoll, Y. T. Gröhn, T. Bolstad, A. Waldmann, and E. Ropstad. 2002. Relationships among body condition score, milk constituents and postpartum luteal function in Norwegian dairy cows. J. Dairy Sci. 85:1406-1415.

van Straten, M., N. Y. Shpigel, and M. Friger. 2009. Associations among patterns in daily body weight, body condition scoring, and reproductive performance in high producing dairy cows. J. Dairy Sci. 92:4375-4385.

VanRaden, P. M., A. H. Sanders, M. E. Tooker, R. H. Miller, H. D. Norman, M. T. Kuhn, and G. R. Wiggans. 2004. Development of a national genetic evaluation for cow fertility. J. Dairy Sci. $87: 2285-2292$

Veerkamp, R. F., E. P. C. Koenen, and G. de Jong. 2001. Genetic correlations among body condition score, yield, and fertility in first parity cows estimated by random regression models. J. Dairy Sci. 84:2327-2335.

Wall, E., S. Brotherstone, J. A. Woolliams, G. Banos, and M. P. Coffey. 2003. Genetic evaluation of fertility using direct and correlated traits. J. Dairy Sci. 86:4093-4102.

Waltner, S. S., J. P. McNamara, and J. K. Hillers. 1993. Relationships of body condition score to production variables in high producing Holstein dairy cows. J. Dairy Sci. 76:3410-3419. 